\title{
COMPARISON OF THE IN VITRO DISSOLUTION PROFILES FOR A HIGH SOLUBILITY DRUG FROM IMMEDIATE RELEASE FORMULATIONS USING USP APPARATUSES 3 AND 4
}

\author{
MONICA ARDELEAN $^{1 \#}$, SILVIA MARIA STOICESCU ${ }^{2 * *}$, CĂTĂLINA LILIANA ANDREI ${ }^{3 *}$, \\ DUMITRU LUPULIASA ${ }^{1,4 \#}$, HORAȚIU MARIUS VIZITEU ${ }^{1,4 \#}$, DALIA SIMONA MIRON ${ }^{4,5 \#,}$ \\ SIMONA ARDELEAN ${ }^{6 \#}$, MIRELA ADRIANA MITU ${ }^{1 \#}$ \\ 1 "Carol Davila” University of Medicine and Pharmacy, Faculty of Pharmacy, Department of Pharmaceutical Technology \\ and Biopharmaceutics, 6 Traian Vuia Street, 020956, Bucharest, Romania \\ 2 "Carol Davila" University of Medicine and Pharmacy, Faculty of Medicine, Department of Obstetrics and Gynaecology, \\ "Polizu" Clinical Hospital, Bucharest, Romania \\ 3 "Carol Davila" University of Medicine and Pharmacy, Faculty of Medicine, Department of Cardiology and Thoracic \\ Pathology, Bucharest, Romania \\ 4 "Carol Davila” University of Medicine and Pharmacy, Faculty of Pharmacy, Center for Drug Sciences (CedS), 6 Traian \\ Vuia Street, 020956, Bucharest, Romania \\ 5 "Carol Davila" University of Medicine and Pharmacy, Faculty of Pharmacy, Department of Pharmaceutical Physics and \\ Informatics, 6 Traian Vuia Street, 020956, Bucharest, Romania \\ "Vasile Goldiș” Western University, Faculty of Pharmacy, Arad, Romania \\ *corresponding author: stoicescusilvia@yahoo.com \\ \#All authors have equally contributed to the current paper.
}

Manuscript received: January 2018

\begin{abstract}
The current paper represents the continuation of a previous report focusing on the role of in vitro dissolution testing in the estimation of the in vivo performance for immediate release solid oral dosage forms containing a BCS class 3 drug, metformin hydrochloride. The methodology was extended by application of alternative compendial apparatuses (flowthrough cells and reciprocating cylinders, using basket or paddle method as reference) and testing of a higher strength (850 $\mathrm{mg}$ ). The experimental results suggested the complementarity of information generated by different hydrodynamic parameters and volumes of media.
\end{abstract}

\section{Rezumat}

Prezenta lucrare reprezintă continuarea unui raport anterior asupra rolului testelor de dizolvare in vitro în estimarea performanței in vivo a formelor farmaceutice solide orale conținând o substanță medicamentoasă din clasa $3 \mathrm{BCS}$, metformin clorhidrat. Metodologia a fost extinsă prin aplicarea unor aparate compendiale alternative (celulele în flux continuu și cilindri cu mişcări alternative, utilizând metodele cu paletă sau coșuleț ca referință) și testarea unei doze mai mari $(850 \mathrm{mg})$. Rezultatele experimentale au sugerat complementaritatea informației generate de parametri hidrodinamici și volume de mediu diferite.

Keywords: in vitro dissolution, BCS class 3, immediate release, reciprocating cylinder, flow-through cell

\section{Introduction}

The utility of the in vitro dissolution methodologies for the evaluation of the quality and potential in vivo performance of oral solid dosage forms containing a high solubility, low permeability drug has been screened previously [1]. The methodologies were direct applications of the specific monographs or adaption based on noncompendial approaches, with notable hydrodynamic differences and variable impact on the disintegration of dosage units and dissolution of metformin hydrochloride as a model drug with limited absorption through the intestinal barrier. Paddle and basket methods are preferred for the development of routine quality control procedures of conventional formulations, based on the considerable experience gained since their official adoption. Both are mentioned as part of the waiver procedures based on the Biopharmaceutics Classification System [2-4], with differences between the guidance documents issued by several regulatory authorities. However, there are known limitations of the dissolution apparatuses, related not only to the hydrodynamics. The conventional round bottom vessels are described as closed systems, with volumes of aqueous fluids of at least $500 \mathrm{~mL}$. The volume used for BCS classification is $250 \mathrm{~mL}$, therefore the utility of small 
vessels has been considered for development of more bio-relevant approaches [5-7].

The standardization of the testing parameters, in order to assess the outcome of the dissolution test as a property of the dosage form combining the drug with excipients in a controlled manufacturing process [8], makes it difficult to simulate in an in vitro setup the complexity of the in vivo phenomena. Particularly the mechanical stress acting on the pharmaceutical dosage unit is a critical factor, as well as the limited and variable volume available for dissolution. The reciprocating cylinder and flow-through cells are mostly used for the assessment of modified release formulations. The availability of several rows of small volume, flat bottom vessels gives the opportunity to simulate the $\mathrm{pH}$ change specific to the gastro-intestinal tract [9, 10]. At the same time, setting the frequency of reciprocating movements allows the control of the shearing forces acting on the solid dosage forms. For the flow-through cells, the versatility and the theoretically unlimited volume of media with more or less hydrodynamic standardization are two of the most frequently mentioned advantages $[11,12]$. In the current version of the general chapter 1092 of the United States Pharmacopoeia [13] it is suggested that its potential application in case of immediate release formulation can provide insights for the very first moments of the dissolution processes. This is of particular importance for instances where very rapid dissolution occurs (more than $85 \%$ of the labelled claimed amount in 15 minutes or less) and it is highly relevant for the elucidation of sources of variability associated with early sampling time in conventional approaches. In this context, it is to be mentioned that recently US Food and Drug Administration issued the final version of the BCSbased biowaiver guidance [4], which extends the application limits to class 3 . Additional requirements of qualitative and quantitative similarity (Q1 and Q2) of the compared immediate release solid dosage forms are included in this attempt of international harmonization [14].

In this paper we present the results of the in vitro dissolution testing of metformin hydrochloride from four marketed immediate release solid oral dosage forms. The methodological approach used comparable parameters, adapted from the available compendial monographs (paddle and basket method) to the particularities of the reciprocating cylinder and flowthrough cells. The aim was to evaluate the impact of the assumed differences in volume of media and its pattern of flow on the kinetics and variability of drug release, as well as their discriminatory character for the known differences in composition between the products.

\section{Materials and Methods}

Four marketed immediate release, pharmaceutically equivalent solid oral dosage forms containing $850 \mathrm{mg}$ metformin hydrochloride were subjected to the in vitro dissolution testing using four distinct methodological approaches, all based on compendial apparatuses. For the paddle and basket method,

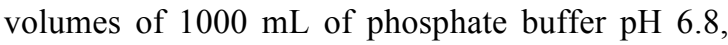
prepared according to USP, were used. The media was degassed by filtration under vacuum. All tests were performed on six replicates, at $37 \pm 0.5^{\circ} \mathrm{C}$. Manual collection of the samples was performed as described previously ( 7 samples per vessel, 60 minutes total duration; [1]), with media replacement. Quantitative analysis of metformin hydrochloride was performed spectrophotometrically at $233 \mathrm{~nm}$, using a validated method [15]. The basket method was applied according to the test 1 of the individual USP monograph (40 mesh conventional basket, at $100 \mathrm{rpm}$ ), with Q value of $70 \%$ fraction dissolved in 45 minutes as acceptance criteria. The paddle method $(75 \mathrm{rpm})$ corresponded to the test 2 , with Q value of $75 \%$ in 30 minutes.

For the reciprocating cylinder, the experimental protocol included Erweka Release Rate Tester BioDis RRT10 equipment (Erweka GmbH, Germany), equipped with polypropylene $420 \mu \mathrm{m}$ screens at both ends of the inner cylinders (lower cap, stainless steel mesh; upper cap, polypropylene mesh). The dosage forms where immersed at a frequency of 20 dips per minute on $10 \mathrm{~cm}$ in $250 \mathrm{~mL}$ aqueous buffer processed as described previously $(300 \mathrm{~mL}$ flat bottom, conventional vessels). The samples were collected 10 seconds after stopping the movements at indicated times and raising of the inner cylinder.

In a distinct approach, the large tablet flow-through cells (22.6 mm inner diameter, $19 \mathrm{~mL}$ volume) were mounted on an Erweka DFZ 720 system (Erweka GmbH, Germany), equipped with a 7 channels HKP 720 piston pump, previously calibrated at $95-105$ nominal flow rate. The cells were filled with a single $5 \mathrm{~mm}$ glass sphere for regulation of unidirectional flow, as well as $7 \mathrm{~g}$ of $2 \mathrm{~mm}$ glass beads, for hydrodynamic standardization (columnar flow; [12]). The outflow was passed though glass fibre filters $(25 \mathrm{~mm}$ diameter, $2.7 \mu \mathrm{m}$ declared mean pores size, type GD/F) and collected fractionally. The conventional tablets were positioned in holder, above the layer of glass beads. A flow rate of $16 \mathrm{~mL} / \mathrm{min}$ was used, leading to a total volume of $960 \mathrm{~mL}$ of buffer media throughout the test duration.

The mean dissolution profiles were cross analysed for comparison of release kinetics, associated variability and discrimination for the assumed differences between tested multisource products. 


\section{Results and Discussion}

Considering the specific compendial monograph, all the four generic film coated tablets fulfil the acceptance criteria for both basket and paddle method (Figure 1 and Figure 2). In fact, the dissolution was complete within 30 minutes and independent on the apparatus (more than $95 \%$ of the label claimed content of metformin hydrochloride). The tested products had a simple composition, qualitatively similar for $\mathrm{A}$ and $\mathrm{C}$ (no information on the technical grade of hydroxypropyl-methylcellulose or povidone was available). The product $\mathrm{D}$, containing a super-disintegrant, represented a particular instance where the dissolution was very rapid independent of the methodology, but highly variable initially.
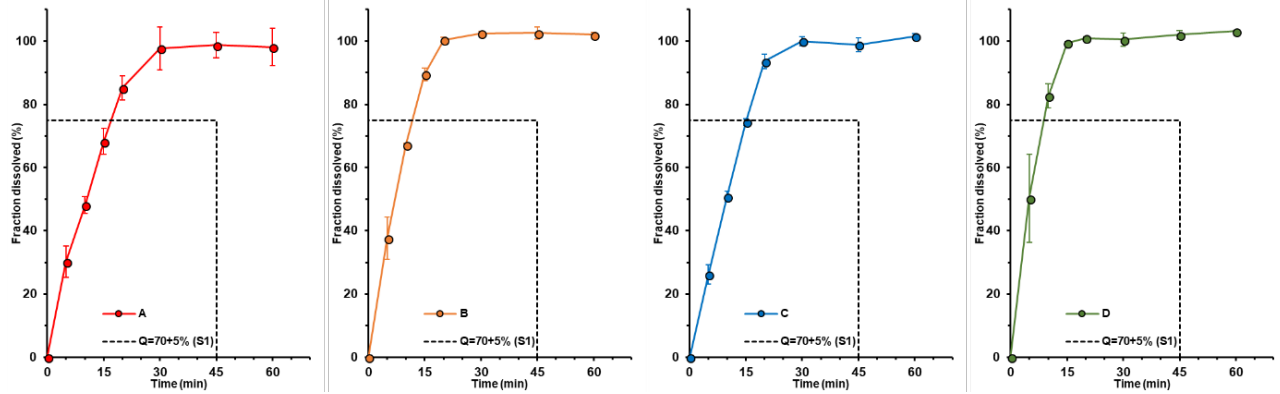

Figure 1.

The in vitro dissolution profiles of metformin hydrochloride from conventional immediate release formulations using the basket method (mean \pm standard deviation, $\mathrm{n}=3$ )

Note: dotted line represents the acceptance criteria according to test 1 (USP individual monograph)
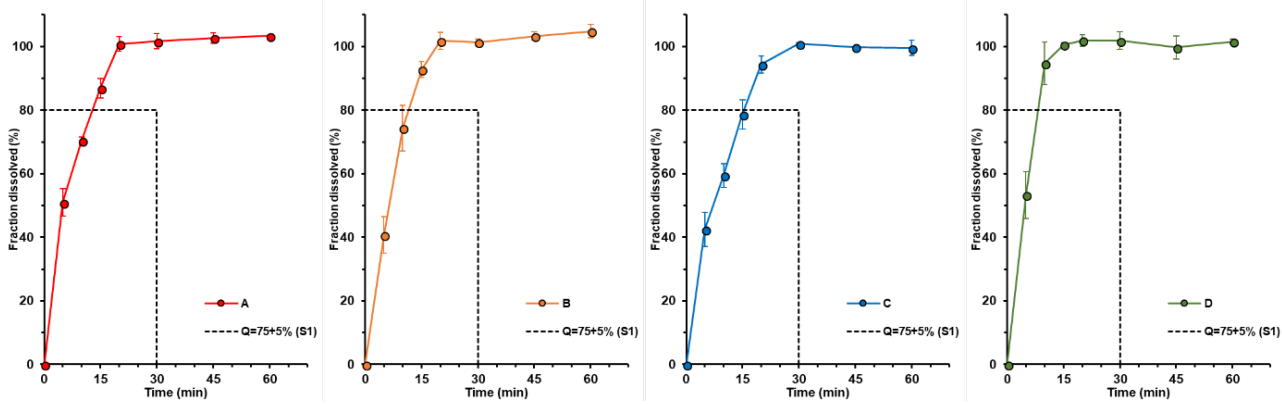

Figure 2.

The in vitro dissolution profiles of metformin hydrochloride from conventional immediate release formulations using the paddle method (mean \pm standard deviation, $\mathrm{n}=6$ )

Note: dotted line represents the acceptance criteria according to test 2 (USP individual monograph)

The reciprocating cylinders exercised a mechanical stress directly onto the solid dosage form, accelerating the disintegration without significant changes of the dissolution rate. The fraction released after 5 minutes is comparable between the four products, with mean differences lower than $10 \%$. However, this is related to generation of large fragments of both drug and excipients, mainly resident onto the lower sieve. Significant expulsion of solid particles occurred after this first sampling, leading the gradual or almost instantaneous complete release. Even thoughl; deposition on the bottom of the vessel was observed, this didn't increase the variability, nor limited the dissolution rate.
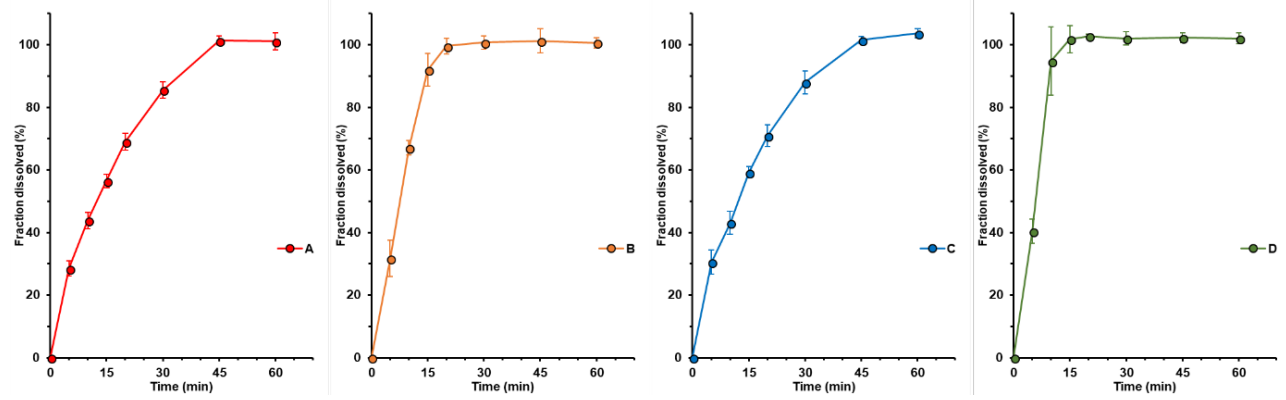

Figure 3.

The in vitro dissolution profiles of metformin hydrochloride from conventional immediate release formulations using the reciprocating cylinders (mean \pm standard deviation, $\mathrm{n}=3$ ) 
The variability distribution profile is different from the flow-through setup. At first sampling point, corresponding to 5 minutes after initiation of the flow, the fractions dissolved are reduced, $1.9 \%$ to $6.2 \%$, with coefficients of variation above $10 \%$ only for the rapidly disintegrating products but below $20 \%$ in all cases. Considering the continuous elution and consecutive collection of the media, these values of the fraction dissolved are possibly reflecting the first 2 - 3 minutes of the analysis. Positioning of the resulting fragments on top of the glass beads layer, as well as their different size during this second half of the test could be an explanation for the apparent increased dispersion of the experimental data.
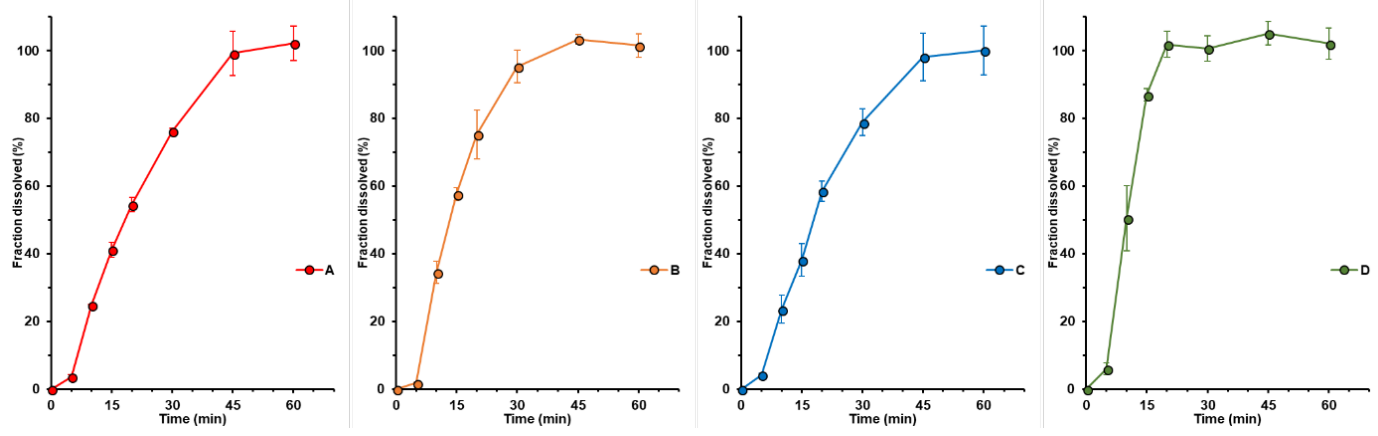

Figure 4.

The in vitro dissolution profiles of metformin hydrochloride from conventional immediate release formulations using the large tablet flow-through cells (mean \pm standard deviation, $\mathrm{n}=3$ )

To be noted, the kinetic discrimination was not altered, meaning that the fraction released at reference time points (15 and 30 minutes) were well within the regulatory limits for definition of rapid (products B and D) and very rapid dissolution (products A and C). It can be assumed that the short lag-time is not related to the performance of the products, but rather a typical methodological artefact, traced back to the length of the outflow circuit. The dosage forms evolved in a limited momentary volume, although continuously replaced by blank media, therefore the dissolution rates are lower compared to the other dissolution apparatuses.

Even though the experimental approach for BCS-based biowaiver procedures is different from the routine quality control, particularly in this case the volume used for paddle and basket methods, the same limits for model-independent kinetic assessment of the mean in vitro dissolution profiles was applied. The data corresponding to the 15 and 30 minutes sampling points are presented in Table I. There are two kinetically-distinct groups, corresponding to the visually observed disintegration pattern. The dissolutions of rapidly disintegrating product coded $\mathrm{B}$ and $\mathrm{C}$ were not significantly influenced by the hydrodynamic and volume dependent particularities of the experimental setup. The same conclusion is valid for the more slowly dissolving products code $\mathrm{A}$ and C. The fraction dissolved for product $A$ at 15 minutes utilizing the paddle method can be considered as a borderline value.

\begin{tabular}{|c|c|c|c|c|c|}
\hline \multirow{2}{*}{ Apparatus } & Time point / & \multicolumn{4}{|c|}{ Product } \\
\cline { 3 - 6 } & kinetics & A & B & C & D \\
\hline \multirow{3}{*}{ Basket } & 15 min & $68.26 \pm 4.08$ & $89.48 \pm 2.06$ & $74.41 \pm 1.03$ & $99.43 \pm 0.52$ \\
\cline { 2 - 6 } & 30 min & $97.68 \pm 6.72$ & $102.47 \pm 0.68$ & $100.00 \pm 1.38$ & $100.47 \pm 2.14$ \\
\cline { 2 - 6 } & Dissolution & Rapid & Very rapid & Rapid & Very rapid \\
\hline \multirow{3}{*}{ Paddle } & 15 min & $86.88 \pm 3.02$ & $92.77 \pm 2.44$ & $78.65 \pm 4.64$ & $100.56 \pm 0.63$ \\
\cline { 2 - 6 } & 30 min & $101.67 \pm 2.46$ & $101.35 \pm 0.97$ & $100.90 \pm 0.26$ & $101.80 \pm 2.76$ \\
\cline { 2 - 6 } & Dissolution & Very rapid & Very rapid & Rapid & Very rapid \\
\hline Reciprocating cylinder & 15 min & $56.47 \pm 2.13$ & $91.95 \pm 5.24$ & $59.19 \pm 1.85$ & $101.77 \pm 4.41$ \\
\cline { 2 - 6 } & 30 min & $85.54 \pm 2.66$ & $100.69 \pm 2.18$ & $87.99 \pm 3.70$ & $101.99 \pm 2.15$ \\
\cline { 2 - 6 } & Dissolution & Rapid & Very rapid & Rapid & Very rapid \\
\hline \multirow{2}{*}{ Flow-through cells } & 15 min & $41.19 \pm 2.17$ & $57.63 \pm 1.85$ & $38.23 \pm 4.81$ & $86.96 \pm 1.86$ \\
\cline { 2 - 6 } & 30 min & $76.26 \pm 0.74$ & $95.30 \pm 4.76$ & $78.81 \pm 3.94$ & $100.67 \pm 3.74$ \\
\cline { 2 - 6 } & Dissolution & Slow & Rapid & Slow & Very rapid \\
\hline
\end{tabular}

The comparison of the mean in vitro dissolution profiles was performed using the EMA (2010) conditions, considering a single time point after the $85 \%$ limit of the dissolved fraction for each product. To be noted, in vitro similarity was assessed within the same product, the goal being to underline the impact of 
FARMACIA, 2018, Vol. 66, 3

each methodology. The results presented in Table II address only to products coded $\mathrm{A}$ and $\mathrm{C}$, where the

calculation of the similarity factors was possible (at least three pairs on mean data available).

Table II

Within product evaluation of in vitro dissolution similarity based on the values of the difference $\left(\mathrm{f}_{1}\right)$ and similarity factors $\left(f_{2}\right)$

\begin{tabular}{|l|c|c|c|c|}
\hline \multicolumn{1}{|c|}{ Comparison } & \multicolumn{2}{c|}{ Product: A } & \multicolumn{2}{c|}{ Product: $\mathbf{C}$} \\
\cline { 2 - 5 } & $\mathrm{f}_{1}$ & $\mathrm{f}_{2}$ & $\mathrm{f}_{1}$ & $\mathrm{f}_{2}$ \\
\hline Basket $v s$. Paddle & - & - & $\mathbf{1 2 . 1 5}^{*}$ & $\mathbf{5 1 . 1 6}^{*}$ \\
\hline Basket $v$ s. Reciprocating cylinder & $\mathbf{1 4 . 6 7 *}$ & 49.26 & 20.41 & 42.11 \\
\hline Basket $v$. Flow-through cells & 46.30 & 28.45 & 49.14 & 25.66 \\
\hline Paddle $v s$. Reciprocating cylinder & - & - & 25.84 & 36.90 \\
\hline Paddle $v s$. Flow-through cells & - & - & 54.65 & 21.24 \\
\hline Reciprocating cylinder $v s$. Flow-through cells & 29.15 & 38.06 & 30.27 & 36.38 \\
\hline
\end{tabular}

* - in vitro similarity concluded

Due to the high solubility profile of the active pharmaceutical ingredient and intense stirring pattern, the paddle and basket method [15] were not able to discriminate between the different compositions. In all the other cases, the main source of the in vitro dissolution non-similarity is to be traced to the initial 15 minutes of the testing procedure. Moreover, the flow-through cells seem to provide the slowest release rates, with distinct dissolution patterns for the same product, when compared to the other three approaches. Presumably, there is an increased biorelevance of the 15 minutes sampling point, because it corresponds roughly to $250 \mathrm{~mL}$ cumulative volume passing through the equipment. When compared to the reciprocating cylinder, the kinetic differences reflect mainly the critical role of the shearing forces induced by the amplitude and frequency of the alternative movements.

It is the authors' personal opinion that the current dissolution criteria for immediate release solid oral dosage forms containing BCS class 3 drugs are too restrictive. Based on in silico simulations, previous reports suggested that, within large limits, dissolution kinetics have not a significant impact on the in vivo exposure parameters [16]. The main limitations in absorption come from the physico-chemical properties of hydrophilic molecules. Theoretically, the location of intestinal absorption windows and the associated transit times necessary for reaching it should be considered in setting the time interval of complete release. This could trigger a case-by-case approach, not feasible for regulatory purposes. The application of various experimental setups, able to emphasize on the in vitro performance of the dosage forms when subject to controlled variables such as mechanical stress or limited volume of aqueous fluid, may be adequate for the bio-inequivalence risk assessment. Recent reports [17] suggest that the requirement of qualitative and quantitative similarity of composition may be too restrictive. The methodologies based on flow-through cells or reciprocating cylinder present several advantages in the evaluation of immediate release dosage forms and should be used as part of an aggregate in vitro similarity assessment.

\section{Conclusions}

The current report illustrates the complementarity of information generated by various methodological approaches based on compendial dissolution apparatuses in case of immediate release solid oral dosage forms containing metformin hydrochloride, a BCS class 3 drug. The flow-through cells and reciprocating cylinders provided alternative insights on the role of mechanical stress and limited momentary volume of aqueous media in dissolution, as the first step for the in vivo absorption. The in vitro test displayed different discriminatory character in relation to the composition of the products, therefore it is suggested that the combined results of several dissolution methods will provide an adequate risk assessment for biowaiver procedures.

\section{References}

1. Ardelean M, Stoicescu SM, Stănescu AA, Lupuliasa D, Stănicioiu DM, Rădulescu FȘ, Miron DS, In vitro dissolution methodology and estimated consequences of biowaiver extension for immediate release solid oral dosage forms with metformin hydrochloride. Farmacia, 2018; 66(1): 18-25.

2. U.S. Food and Drug Administration, Center for Drug Evaluation and Research. Guidance for industry: Waiver of in vivo bioavailability and bioequivalence studies for immediate-release solid oral dosage forms based on a Biopharmaceutics Classification System, 2000. www.fda.gov/ohrms/dockets/98fr/3657gd3.pdf.

3. European Medicine Agency, Committee for Medicinal Products for Human Use. Guideline on the investigation of bioequivalence. 2010. www.emea.europa.eu/docs/ en_GB/document_library/Scientific_guideline/201 0/01/WC500070039.pdf.

4. U.S. Food and Drug Administration, Center for Drug Evaluation and Research. Guidance for industry: Waiver of in vivo bioavailability and bioequivalence studies for immediate-release solid oral dosage forms based on a Biopharmaceutics Classification System. 2017. www.fda.gov/downloads/Drugs/Guidance 
ComplianceRegulatoryInformation/Guidances/UC M070246.pdf.

5. Scheubel E, Lindenberg M, Breyssac E, Cardot JM, Small volume dissolution testing as a powerful method during pharmaceutical development. Pharmaceutics, 2010; 2(4): 351-363.

6. Klein S, Shah VP, A standardized mini paddle apparatus as an alternative to the standard paddle. AAPS PharmSciTech., 2008; 9(4): 1179-1184.

7. Klein $\mathrm{S}$, The mini paddle apparatus - a useful tool in the early developmental stage? Experiences with immediate-release dosage forms. Dissolut Technol., 2006; 13: 6-11

8. Saramet G, Rădulescu FS, Miron DS, Bărbuceanu ȘF, Stănescu AA, Vlaia L, Piţuru S, Lupuliasa D, Study describing the formulation and the release of some active pharmaceutical ingredients from HPMC hydrophilic matrix tablets. Note I. Farmacia, 2017; 65(5): 690-697.

9. Cacace J, Reilly EE, Amann A, Comparison of the dissolution of metaxalone tablets (Skelaxin) using USP apparatus 2 and 3. AAPS PharmSciTech., 2004; 5(1): 29-31.

10. da Silva MGR, Volpato NM, Pinto EC, Cabral LM, de Sousa VP, Development of a dissolution test for extended-release bromopride pellets with in vivo-in vitro correlation. Dissolut Technol., 2015; 22: 24-33.

11. Fotaki N, Reppas C, The Flow Through Cell Methodology in the Evaluation of Intralumenal Drug
Release Characteristics. Dissolut Technol., 2005; 12: 17-21.

12. Fotaki N, Flow-through cell apparatus (USP Apparatus 4): Operation and features. Dissolut Technol., 2011; 18(4): 46-49.

13. United States Pharmacopoeia 39 - National Formulary 34, 2016. Chapter 1092: The dissolution procedure: development and validation, U.S. Pharmacopeial Convention, Rockville, MD 20852.

14. Davit BM, Kanfer I, Tsang YC, Cardot JM, BCS Biowaivers: Similarities and Differences among EMA, FDA, and WHO Requirements. AAPS J, 2016; 18(3): 612-618.

15. United States Pharmacopoeia 39 - National Formulary 34, 2016. Metformin hydrochloride tablets, United States Pharmacopeial Convention, Rockville, MD 20852.

16. Tsume Y, Amidon GL, The biowaiver extension for BCS class III drugs: The effect of dissolution rate on the bioequivalence of BCS class III immediaterelease drugs predicted by computer simulation. Mol. Pharm., 2010; 7(4): 1235-1243.

17. Parr A, Hidalgo IJ, Bode C, Brown W, Yazdanian M, Gonzalez MA, Sagawa K, Miller K, Jiang W, Stippler ES, The effect of excipients on the permeability of BCS Class III compounds and implications for biowaivers. Pharm Res., 2016; 33: 167-176. 